\title{
Resolução do escoamento em um furo circular utilizando a fluidodinâmica computacional
}

\author{
Raphael Ferreira Perez ${ }^{\star}$, Paulo Vatavuk
}

\section{Resumo}

O presente projeto de iniciação científica possui como objetivo validar 1) a aplicação de uma abordagem computacional para calcular o coeficiente de descarga $\mathrm{Cd}$, no escoamento com superfície livre, através de um furo circular vertical 2) assim como o software empregado para tal, uma ferramenta de código aberto denominada OpenFOAM. As simulações numéricas foram realizadas buscando reproduzir resultados clássicos de Lea (1938), que estudou o efeito do número de Reynolds $(\mathrm{Re})$ no escoamento. Foram feitas simulações para três valores distintos de $\operatorname{Re}(40,330$ e 26000$)$ e dois valores ( 0 e $2 \mathrm{~mm}$ ) para a espessura da parede que contém o furo. Para avaliar o efeito da malha nos resultados, foi utilizado o procedimento recomendado por Celik (2008), em que são utilizadas três malhas numéricas distintas, com refinamento progressivo. Concluiu-se que as simulações apresentaram bom acordo com os resultados experimentais, respeitadas as incertezas inerentes aos cálculos numéricos.

\section{Palavras-chave:}

Fluidodinâmica computacional (CFD), coeficiente de descarga, OpenFOAM.

\section{Introdução}

Cada vez mais a utilização de recursos computacionais complementa as abordagens tradicionais de pesquisa, teórica e experimental, para a realização de estudos em Hidráulica e Mecânica dos Fluidos. Denominada CFD, a fluidodinâmica computacional emprega modelos de discretização para obter aproximações de soluções de escoamentos e, com devidos cuidados quanto à validação de resultados, possibilita simular inúmeros problemas, inclusive aqueles impraticáveis em termos de modelagem física experimental.

Dentre os vários problemas de Hidráulica, o escoamento aberto através de um furo circular é consagrado e amplamente observado em aplicações de Engenharia. Dentre os parâmetros observados, destacase o chamado coeficiente de descarga, Cd, utilizado para conformar vazões teóricas às de fato observadas, visto que durante escoamentos livres há formação de uma veia contraída de água, ou jato, após o elemento. Frequentemente adotado como 0.611 , este coeficiente varia conforme o diâmetro do furo e a carga hidráulica sobre ele. Diferentes autores apresentam valores distintos para o mesmo em situações similares. Assim, propõe-se simular e calcular valores de Cd com o auxílio de uma ferramenta computacional de código aberto, chamada OpenFOAM, amplamente difundida entre pesquisadores, a fim de validar a utilização de recursos tecnológicos e o próprio software em pesquisas acadêmicas a nível de graduação.

\section{Resultados e Discussão}

A fim de estimar o erro associado ao coeficiente determinado em cada simulação, recorreu-se à metodologia proposta por Celik (2008); com ela inicialmente averiguou-se o conjunto de dados de Lea (1938), conforme figura 1, e para varrer um intervalo significativo de números de Reynolds, foram escolhidos: $\operatorname{Re}=\{40 ; 330 ; 26000\}$. Com eles, simulou-se o escoamento através de um furo circular vertical de $1 \mathrm{~cm}$ de raio com uma vazão de $0.406 \mathrm{l} / \mathrm{s}$; como mencionado, para cada Re executou-se três estudos, um por malha numérica, com um nível de refinamento crescente. Além disto, avaliou-se duas situações: uma com um furo de espessura nula e outra com um de $2 \mathrm{~mm}$ de espessura.

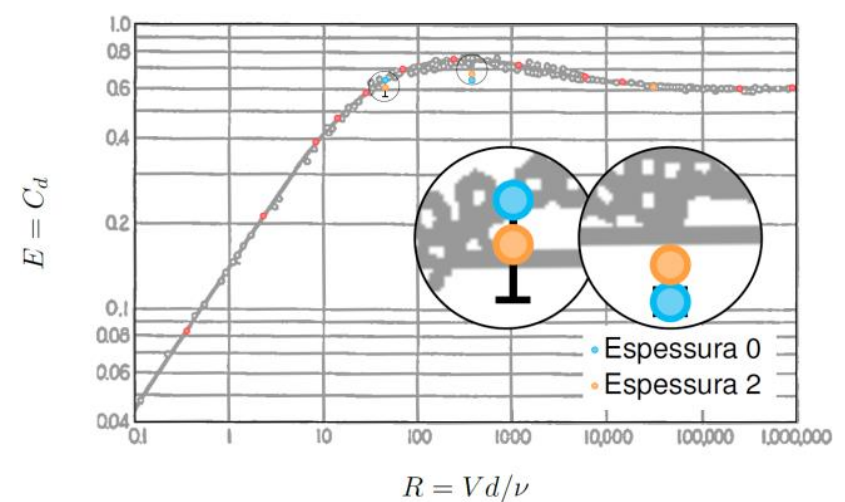

Figura 1. Valores calculados sobre dados de Lea (1938)

Tabela 1. Resultados obtidos conforme Re e espessura

\begin{tabular}{cccc}
\hline & $\boldsymbol{R e} \mathbf{4 0}$ & $\boldsymbol{R e} \mathbf{3 3 0}$ & $\boldsymbol{R e} \mathbf{2 6 0 0 0}$ \\
\cline { 2 - 4 } $\mathbf{0} \mathbf{~ m m}$ & $0.635 \pm 0.003$ & $0.63 \pm 0.01$ & $0.5996 \pm 0.0005$ \\
$\mathbf{2 ~} \mathbf{m m}$ & $0.60 \pm 0.04$ & $0.667 \pm 0.005$ & $0.600 \pm 0.006$ \\
\hline
\end{tabular}

Para validar o obtido, plotou-se os pares de dados sobre a figura 1, como é possível observar acima. Nota-se que, exceto para $R e=40$, situação em que possivelmente a viscosidade afetou o escoamento, todos os erros aferidos estão abaixo de $2 \%$ e, como as barras de erro interceptam, para a maioria dos valores obtidos, a curva teórica, verifica-se que os coeficientes concordam com o esperado teoricamente.

\section{Conclusões}

Após implementar uma metodologia informatizada de cálculo de um coeficiente de descarga hidráulico e validar os resultados obtidos, conclui-se que o objetivo proposto, de apresentar uma abordagem tecnológica e um software alternativos, foi devidamente atendido.

\section{Agradecimentos}

Os autores gostariam de agradecer o Conselho Nacional de Desenvolvimento Científico e Tecnológico (CNPq) e a Pró-Reitoria de Pesquisa da Universidade Estadual de Campinas por estimularem esta pesquisa.

${ }^{1}$ CELIK, I. B. Procedure for Estimation and Reporting of Discretization Error in CFD Applications. Journal of Fluids Engineering. ASME, 2008.

2 LEA, F. C. Hydraulics for engineers and engineering students. Arnold, 1938. 